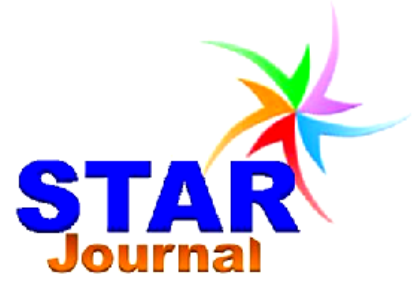

ISSN: 2226-7522(Print) and 2305-3327 (Online) Science, Technology and Arts Research Journal

\title{
Acceptability of Provider Initiated HIV Counseling and Testing in Pregnant Mothers Attending ANC at Nekemte Town Government Health Facilities
}

\author{
Tahir Hasen \\ College of Medical and Health Sciences, Wollega University, Post Box No: 395, Nekemte, Ethiopia
}

\begin{tabular}{|c|c|}
\hline Abstract & \\
\hline \multirow{13}{*}{$\begin{array}{l}\text { The present study was designed to determine the acceptability of PIHCT on pregnant } \\
\text { mothers attended ANC at Nekemte government health facilities. A cross-sectional study } \\
\text { was conducted from May } 1 \text {, to June } 7,2009 \text {. Modified standardized questionnaires and } \\
\text { in-depth interviews were used. Total } 422 \text { participants were involved, of these } 274 \text { from } \\
\text { Nekemte hospital and } 148 \text { from Nekemte health center with } 100 \% \text { response rate. The } \\
\text { mean age of the participants were } 24.24 \text { with SD of } 5.02 \text { and their age ranges were } 16 \text { to } \\
40 \text {. The overall acceptability rate was } 370(87.7 \%) \text {. Almost all the respondents } 412(97.6 \%) \\
\text { were knowledgeable to the three cardinal ways of prevention of HIVIAIDS (i.e. } \\
\text { Abstinence, avoiding multiple sexual partners and sharing sharps). But } 151(35.8 \%) \text { were } \\
\text { knowledgeable to the three methods of HIV transmission from mother to child during } \\
\text { pregnancy, child birth \& breast feeding. Three hundred ten ( } 73.9 \%) \text { of the mothers } \\
\text { perceived themselves not at risk of HIVIAIDS. Pre-test counseling was given for } \\
337(79.9 \%) \text { of the mothers ( } P=0.002) \text {. Health workers } 260(61.6 \%) \text { were the most } \\
\text { common source of information. Media and religious leaders played a little role in } \\
\text { dissemination of information. Acceptability to PIHCT in this study is remarkable. } \\
\text { Improving participation of religious leaders and HCWs by giving continuous in-service and } \\
\text { pre-service training, couple counseling and designing strategies on change of attitude and } \\
\text { practice were recommended }\end{array}$} & rrticle History: \\
\hline & Received : 19-06-2012 \\
\hline & Revised : 29-08-2012 \\
\hline & Accepted : 05-09- \\
\hline & Keywords: \\
\hline & tability \\
\hline & $\mathrm{PIH}$ \\
\hline & Satisf \\
\hline & Nekemte \\
\hline & ${ }^{\star}$ Corresponding Author: \\
\hline & Tahir Hasen \\
\hline & E-mail: \\
\hline & \\
\hline
\end{tabular}

\section{INTRODUCTION}

HIV counseling and testing (HCT) is a key strategic entry point to prevention, treatment, care and support services. This is critically important for individuals and couples to learn about their HIV status and make informed decisions about their future (Federal HAPCO, 2004)). In all types of HIV epidemics, health care providers should recommend HIV testing and counseling as part of the standard of care to all adults, adolescents or children who present to health facilities with signs, symptoms or medical conditions that could indicate HIV infection. HIV testing and counseling as early as possible during pregnancy enables pregnant women to benefit from prevention, treatment and care and to access interventions for reducing HIV transmission to their infants (Public Health Agency of Canada, 2006).
A substantial proportion of women present to health facilities at the time of labor without having previously accessed antenatal HIV testing and counseling. Although antiretroviral prophylaxis for PMTCT is most effective when given during pregnancy, labor and in the early postpartum period, it has also been shown to be effective when started at the time of labor and/or in the infant shortly after childbirth (WHO/UNAIDS, 2004). Therefore, HIV testing and counseling should be recommended to all women of unknown HIV status in labor or, if this is not feasible, as soon as possible after delivery.

Despite recent progress, at the end of 2006 an estimated 39.5 million people globally were living with HIV, and more than 4 million new HIV infections occurred in that year. Sub-Saharan Africa remains the most affected region, with 24.7 
Tahir Hasen

million people living with HIV (nearly two-thirds of the global burden), while epidemics in Eastern Europe and Asia continue to grow (Stein and Nyamathi, 2000).

Surveys in sub-Saharan Africa have shown that a median of just $12 \%$ of men and $10 \%$ of women had been tested for HIV and received the results. The result of low coverage and uptake of HIV testing and counseling and low levels of knowledge of HIV status is that the majority of people living with HIV access, HIV testing and counseling only when they already have advanced clinical disease (Federal HAPCO, 2004). Some treatment programmes have reported high early mortality in patients receiving antiretroviral therapy because of late presentation (Paxton et al., 2005).

Despite the increasing number of HIV treatment programs in resource poor settings however, uptake of testing is often low and many patients are being diagnosed only when they are profoundly immune-suppressed (Coetzee et al., 2004). Acceptance rates of between 53\%-99.7\% were reported from various sites in sub-Saharan Africa (Wilkinson et al., 1997).

Ethiopia responded to the HIVIAIDS epidemic as early as 1985 . The Federal Ministry of Health and the HIVIAIDS Prevention and Control Office (MOH/HAPCO) developed an HIVIAIDS policy, different guidelines (PMTCT, ART, IP, VCT etc) and strategic documents to create an environment conducive for the implementation of HIV prevention, care and treatment and support programs. As part of this effort, the first counseling and testing guidelines were published by the federal Ministry of Health (FMOH) in 1996 and the second edition, currently in use, in 2002 (Federal HAPCO, 2004).

The HIVIAIDS prevalence is high in Nekemte town. It was the third next to "Adama" and "Mettu". But according to the 2004/05 Hospital VCT report it stands first from the region (13\%) (Statistical Abstract of FDRE, 2004). Therefore, the aim of this study will be to determine the level of acceptance of pregnant mothers under the initiation of provider initiated HIV counseling and testing in Nekemte hospital and health center.

\section{MATERIALS AND METHODS}

\section{Study Area}

Study was conducted in Nekemte hospital and health center found in western part of Ethiopia east Wollega zone, Oromia region, $331 \mathrm{~km}$ far away from Addis Ababa.
Sci. Technol. Arts Res. J., July-Sep 2012, 1(3): 24-30

\section{Study Design}

A cross-sectional study was conducted in Nekemte hospital and health center.

\section{Study Period}

The study was conducted from May 1, to June 1, 2009.

\section{Source Population}

All Pregnant women who attended ANC in Nekemte hospital and health center were included.

\section{Study Population}

The study subjects were all pregnant women who attended ANC at government health facilities (Nekemte hospital and health center) were included in a study from $1^{\text {st }}$ May to $1^{\text {st }}$ June 1 , 2009.

\section{Sample Size}

To obtain minimum sample size, the population proportion for prevalence of acceptability of PIHCT were taken to be $50 \%$, with the margin of error (desired precision) $5 \%$, $95 \%$ confidence interval. The total population is expected to be greater than 10,000 . The actual sample size was calculated using single proportion formula $n=$ the total sample size (422).

\section{Sampling Methods}

The sampling technique selected was systematic sampling. The data contains quantitative and qualitative analysis. The pregnant mothers attended the hospital and the health center daily were ranging from 35-55 with 45 was the average. The data collection was conducted for 1month (20 working days), from May 1, to June 1, $2009(45 \times 20$ days=900). The sample size calculated was $422(900 / 422=2.13)$. Therefore, the data collection was done 1:2 mothers who attended the health institution.

\section{Data Collection Techniques and Procedures}

For quantitative data, modified standard questionnaires were used and for qualitative data, in-depth interviews and the interview were tape recorded. The questionnaires were translated to the local language (Oromiffaa) and (Amharic). Great care was taken during the training and supervision to avoid differences in interpreting the interview schedule. 
Tahir Hasen

\section{Data Quality control Methods}

To maximize the quality of data, the proposal was seen by the Institutional Review Board of Addis Ababa University and ethical considerations were critically reviewed, data collectors were trained. Study participants were told that their responses were extremely confidential at any circumstance. They were not coerced to participate in the study. Pre-test was done on $10 \%$ of the sample size. Supervisions were done every day during data collection time to each data collector.

\section{Ethical Consideration}

In order to conform to the ethical and legal standards of the scientific investigation, the proposal was seen by the Institutional Review Board (IRB) of Addis Ababa University (AAU) and permission was granted from AAU, Oromia regional health bureau, East Wollega zonal health bureau and Nekemte hospital and health center. The HIV status of the interviewed mothers was unknown to all. The interview work place in a separate room in the ward, and the answers were treated anonymously. Participation was voluntary. They were also told that the information obtained from them would be treated with complete confidentiality.
Sci. Technol. Arts Res. J., July-Sep 2012, 1(3): 24-30

\section{Data Entry and Analysis}

The questionnaire was checked by supervisor (principal investigator) for its completeness and entered in SPSS for windows (version 16) and analysis was done using multivariate logistic regression. Statistical significance was evaluated at 0.05 levels of significance. Descriptive statistics, $\mathrm{X}^{2}$ test and odds ratios were applied.

\section{RESULTS}

\section{Sociodemographic Profile of Participants}

Totally there were 422 participants involved in the study, of these 274 respondents were interviewed from Nekemte hospital and the rest 148 from Nekemte health center with 100\% response rate. The mean age of the study participants were 24.24 \pm 5.02 and their age ranges were 16 to 40 .

Protestant is the leading religion with $232(55 \%)$, Oromo accounts $357(84.6 \%)$ of the participants. Of the respondents $401(95 \%)$ were married. Most, $170(40.3 \%)$, of the pregnant mothers had primary education (grade 1-6) followed by illiterates $111(26.3 \%)$, secondary school $85(20.1 \%)$ and above secondary school were 56(13.3\%). Two hundred sixty eight $(63.5 \%)$, were housewives followed by government employee 56(13.3\%) and data's were represented in Table 1.

Table 1: Sociodemographic variables of respondent's acceptability to PIHCT in Nekemte government health facilities.

\begin{tabular}{lccc}
\hline $\begin{array}{l}\text { Sociodemographic } \\
\text { Variables }\end{array}$ & Number & $\%$ & $\begin{array}{c}\text { Cumulative } \\
\text { Frequency }\end{array}$ \\
\hline Ethnicity & 357 & 84.6 & 84.6 \\
Oromo & 39 & 9.2 & 93.8 \\
Amhara & 15 & 3.6 & 97.4 \\
Tigre & 11 & 2.6 & $100 \%$ \\
Gurage & 422 & 100 & \\
\hline Total & & & \\
\hline Educational Status & 111 & 26.3 & 26.3 \\
Illiterate & 170 & 40.3 & 66.6 \\
Primary & 85 & 20.1 & 86.7 \\
Secondary & 56 & 13.3 & 100 \\
Above secondary & 422 & & \\
\hline Total & & & \\
\hline Marital Status & 401 & 95.0 & 95 \\
Married & 11 & 2.6 & 97.6 \\
Unmarried & 7 & 1.7 & 99.3 \\
Divorced & 3 & 0.7 & 100 \\
Widowed & $\mathbf{4 2 2}$ & $\mathbf{1 0 0 \%}$ & \\
\hline \multicolumn{1}{r}{ Total } & & \\
\hline
\end{tabular}




\section{Proportion of Acceptability of Respondents to PIHCT}

The overall acceptability rates of the respondents were $370(87.7 \%)$ and data were represented in Figure 1. Percentage of acceptability increases with increasing age. Three hundred twelve (87.4\%) Oromo, 34(87.2\%) Amhara, 13(86.7\%) Tigre and 10(100\%) Gurage ethnic groups were willing to PIHCT. Among the marital status, 353(88\%) married, 7(63.6\%) unmarried, $7(100 \%)$ divorced and $3(100 \%)$ widowed mothers were willing to PIHCT. Moreover, 100(90.0\%) illiterates, 141(82.9\%) those attended secondary school, 79(90.0\%) primary school and $50(90.0 \%)$ of those above secondary school were willing.

Almost all the respondents 412(97.6\%) were knowledgeable about the three cardinal ways of prevention of HIVIAIDS (i.e. Abstinence, avoiding multiple sexual partners \& sharing sharps) but $151(35.8 \%)$ of the respondents were knowledgeable to the three methods of HIV transmission from mother to child during Pregnancy, child birth \& breast feeding.

Three hundred ten (73.9\%) of the respondents perceived themselves not at risk of contracting HIVIAIDS. The HCWs had given pre-test counseling for $337(79.9 \%)$ of the mothers and the rest with no pre-test counseling. Of those, who were given pre-test counseling, 304(90.2\%) and $66(77.6 \%)$ who were not given were willing to accept PIHCT with a statistical significance association $\left(P=0.002, X^{2}=9.25, O R=2.744(1.466\right.$ 5.136), $d f=1)$.

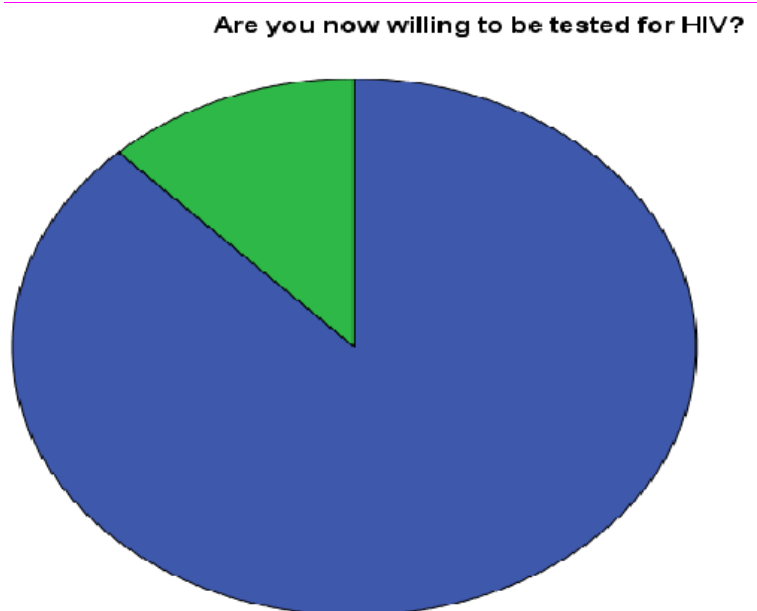

Figure 1: Total acceptability rates of respondents to PIHCT in Nekemte government health facilities.

\section{Factors Affecting Acceptability to PIHCT}

Regarding the information to PIHCT, $334(79.1 \%)$ had the information. Of the 334 pregnant mothers who had the information $298(89.2 \%)$ and of those who did not have the information $73(83 \%)$ were willing. Among the respondents who said $\mathrm{PIHCT}$ is important to pregnant mothers 399(94.6\%) and 23(47.8\%) who said PIHCT is not important were willing to PIHCT with a statistically significant association $\left(P=0.00, X^{2}=23.837, \quad O R=10.070(4.167-24.334)\right.$, $\mathrm{df}=1$ ).

The sources of information to PIHCT were health workers 260(61.6\%), Medias 46(10.9\%), friends $26(6.2 \%)$ and religious leaders $2(0.7 \%)$. Among the respondents who got the information from HCWs 237(91.2\%) ( $P=0.017, \quad O R=2.322$ (1.164-4.634), df=1), were willing to PIHCT. The majority of the mothers $399(94.5 \%)$ responded that PIHCT is important. Regarding benefits of PIHCT to pregnant mothers, most of them replied three of the alternatives (It motivates mothers to be tested, knows self and PMTCT (43.6\%).

Concerning the preferred sex of the counselor, $307(72.7 \%)$ of the respondents answered they had no problem for either sex. The reasons for refusing HIV test were fear of stigma and discrimination $171(40.5 \%)$, fear of violence \& divorce $101(23.9 \%)$, Fear of severity of the disease $76(18.0 \%)$, Fear of losing job \& economic problems $43(10.2 \%)$ and $31(7.3 \%)$ refused the test as they feel healthier.

\section{Satisfaction of Pregnant Mothers to PIHCT}

The percentages of mothers satisfied by the HCWs were 372(88.2\%). Among these, $337(90.6 \%)$ who were satisfied and $33(66 \%)$ who were not satisfied with the care given to them were willing to PIHCT having statistically significant association $\left(P=0.00, \quad X^{2}=16.383\right.$, $\mathrm{OR}=4.531(2.276-9.021), \mathrm{df}=1)$.

\section{DISCUSSION}

HIV testing during pregnancy enables pregnant women to benefit from prevention, treatment and care and to access interventions for reducing HIV transmission to their infants. In this study, among the sociodemographic variables even though age had no statistically significant association with willingness, the percentages of willingness increases as age increases (82.5\%, 87.3\%, 90.4\% and 100\%). This indicates that as age increases responsibility to the family and the value for life increases. This 
Table 2: Distribution of selected variables having statistical association with willingness to PIHCT.

\begin{tabular}{|c|c|c|c|}
\hline \multirow{2}{*}{ Variables } & \multicolumn{2}{|c|}{ Willingness } & \multirow[b]{2}{*}{ Odds Ratio } \\
\hline & Yes & No & \\
\hline \multicolumn{4}{|c|}{ Importance of PIHCT } \\
\hline Yes & 360 & 39 & $10.07(4.167-24.334)$ \\
\hline No & 11 & 12 & - \\
\hline Total & 371 & 51 & \\
\hline \multicolumn{4}{|c|}{ Source of information } \\
\hline From Partner & 237 & 23 & 2.322(1.164-4.634) \\
\hline \multicolumn{4}{|c|}{ Pre-test counseling given } \\
\hline Yes & 304 & 33 & $2.744(1.466-5.136)$ \\
\hline No & 66 & 19 & \\
\hline Total & 370 & 52 & \\
\hline \multicolumn{4}{|c|}{ Information to PIHCT } \\
\hline Yes & 298 & 36 & 10.07(4.167-24.334) \\
\hline No & 72 & 16 & \\
\hline Total & 370 & 52 & \\
\hline \multicolumn{4}{|c|}{ Mothers satisfaction } \\
\hline Yes & 337 & 35 & 4.531(2.276-9.021) \\
\hline No & 33 & 17 & \\
\hline Total & 370 & 52 & \\
\hline \multicolumn{4}{|c|}{ Degree of satisfaction } \\
\hline highly & 193 & 14 & $\mathbf{9 . 1 9 0}(1.1417-59.608)$ \\
\hline Moderately & 126 & 11 & 7.636(1.151-50.666) \\
\hline Total & 319 & 25 & \\
\hline
\end{tabular}

finding is in line with a study conducted in Addis Ababa; showed patients in older age $(>\mathrm{or}=25)$ were found four times more likely willing to PIHCT than younger ages (Melaku, 2007).

In this study, Variables like educational status, higher income and marital status had no statistical significance with PIHCT. This finding is in line with a study conducted in Gondar, indicated that educational status didn't show statistically significant association with HIV testing (Alemu et al., 2004). But different findings were obtained from the study conducted in Jimma and Addis Ababa, Teklehayimanot higher clinic and Gandi hospital found out that better educational status was associated with a higher chance of VCT acceptance (Demissie et al., 2000).

Almost all the respondents $412(97.6 \%)$ were knowledgeable about the three cardinal ways of prevention of HIVIAIDS (i.e. Abstinence, avoiding multiple sexual partners \& sharing sharps). This finding is consistent with a study conducted in Nigeria showed almost all the women (96.1\%) were willing to undergo HIV testing in pregnancy particularly if it would assist preventing transmission of HIV to their babies; but only few would undergo the test if the result would be shared with relatives.

One hundred fifty one $(35.8 \%)$ of the respondents were knowledgeable to the three methods of HIV transmission from mother to child during Pregnancy, child birth \& breast feeding. In FGD (focus group discussion), five respondents (62.5\%) replied, "ARV drugs only helps to prolong the life of the mother but not helpful for the fetus." This finding is almost comparable with the study done in Gambia the majority of pregnant women $(65 \%)$ and $(51 \%)$ had high knowledge on the modes of HIV transmission and on MTCT of HIV 
Tahir Hasen

respectively. Nearly half of the women had low knowledge on specific areas of MTCT such as the transmission of the virus through pregnancy, delivery and breastfeeding (Jammeh, 2007).

Nearly $3 / 4^{\text {th }}(73.9 \%)$ of the respondents had perceived themselves not at risk of contracting HIVIAIDS. From the FGD, six of the eight respondents $(75 \%)$ perceived themselves not at risk of HIV infection. A recent report from Ethiopia and several African countries suggested that self-risk perception of being HIV infected has major influence on HIV test acceptability (Dabis, et al., 2006; WHO/UNAIDS, 2004). A striking finding of this study was that significant proportion of mothers $(87.5 \%)$ had no risk perception for HIV infection. This finding is incomparable to those in other studies conducted in Ethiopia and elsewhere (Dabis et al., 2006), Federal HAPCO, 2004). This finding is higher than results reported from Debrebirhan, where only $4.5 \%$ of youth had HIV risk perception (Melaku, 2007).

The findings of this study indicated, acceptability is highest in those who discussed with their Partner 286(67.8\%). This showed that mothers were more interested to accept information and put into practice when they heard from their partner. So partner involvement is important than any other family members. Discussing with sexual partner has statistical significance with willingness $(P=0.017$, $\mathrm{OR}=2.322(1.164-4.634))$. Willingness increased more than two times when mothers were discussing with their partner. This finding is in accordance with the study done in Gambia the majority of the respondents (97\%) would like to notify their partners about an HIV seropositve result and two third preferred to seek VCT together as a couple. Neighbors and other community members would never be informed of an HIV positive result \& $80 \%$ of the respondents would not discuss their HIV serostatus openly if they were positive (Jammeh, 2007).

From the total pregnant mothers who participated in this study $87.7 \%$ of them were willing to PIHCT and in the FGD, all the respondents were willing to PIHCT. This finding is in line with the study conducted in Addis Ababa that showed $86 \%$ of the patients were willing to accept PIHCT (Melaku, 2007).

In this study, the HCWs had given pre-test counseling for $79.9 \%$ of the mothers and $20.1 \%$ of them been undergone the test with no pre-test counseling with a statistically significant association $\left(P=0.002, \quad X^{2}=9.25, \quad O R=2.744\right.$
Sci. Technol. Arts Res. J., July-Sep 2012, 1(3): 24-30

(1.466-5.136), $d f=1)$. This statistical significance showed that respondents who counseled were at least three times more willing than those who were not counseled. This is nearly comparable with the study done in Gambia the majority (92\%) had gone through the pre-test counseling, but $82 \%$ have actually done an HIV test of which $72 \%$ had taken the decision independently (Jammeh, 2007).

Satisfaction level and willingness to PIHCT have statistical significant association $(P=<0.05$, $\mathrm{OR}=4.531(2.276-9.021)$ ). Mothers who were satisfied with the care provided to them were at least three times more satisfied than those not satisfied. Furthermore, pregnant mothers who were very much satisfied with the care given to them were almost ten times more willing than those who were not satisfied and those who were much satisfied were at least 8 times more satisfied than those not satisfied.

\section{CONCLUSION}

In this study, acceptability of pregnant mothers to PIHCT revealed a significant result. The overall acceptability rate was high $87.7 \%$. The study gives useful information to health care providers to introduce measures that could improve the utilization of antenatal HIV testing.

The sociodemographic characteristics of respondents did not have significant statistical association with acceptability to PIHCT. The study showed as age increases acceptability to PIHCT increases because responsibility to the family and the value for life increases. There was no as such problem of knowledge regarding methods of prevention of the virus but low results $(35.8 \%)$ were obtained on the methods of transmission of HIV from mother to child during Pregnancy, child birth \& breast feeding. Risk perception to HIVIAIDS was considered to be low. Mothers who were given pre-test counseling were more willing than those not counseled.

Client-provider relationships were the pivotal point for the success of acceptability to PIHCT. Therefore it is believed that improving the accessibility and affordability of ARVs to HIV positive individuals, Partner involvement and encouraging couple counseling, Improve participation of religious leaders and media, Pretest counseling, designing Strategies on change of attitude and practice, the integration of PIHCT into routine antenatal care services nationwide, improving the relationships of HCWs and mothers by providing continuous training for HCWs were recommended. 
Tahir Hasen

\section{ACKNOWLEDGEMENTS}

I am grateful to Addis Ababa University, the IRB, School of Nursing, School of Community Health and HAPCO AIDS resource center for their continual support and instructions. I would like to offer my deepest appreciation and thank to my advisor Ato Hussein Mekonnen (MPH). My sincere gratitude and appreciation to Nekemte hospital, Nekemte Health center and Nekemte health Science College.

\section{REFERENCES}

Shitaye Alemu., Nuru Abseno., Getu Degu., Yared Wondmikun., Solomon Amsalu. (2004). Knowledge and Attitude Towards VCT. A Community Based Study in North West Ethiopia. Ethiopian Journal of Health Department 18(2): 82-89.

David Coetzee., Katherine Hildebrand., Andrew Boulle., Gary Maartens, Francoise Louis, Veliswa Labatala

Hermann Reuterc, Nonthutuzelo Ntwanac and Eric Goemaerec (2004). Outcomes after Two Years of Providing Antiretroviral Treatment in Khayelitsha, South Africa. AIDS 18:887-895.

Dabis, F., Egger, M. and Schechter, M. (2006). Mortality of HIV-1-Infected Patients during the First Year of Potent Antiretroviral Therapy: Comparative Analysis of Databases From Low- and High Income Countries. Lancet, 367:817-24.

Demissie, M., Lindtjørn, B., Tegbaru, B. (2000). Hunan Immunodeficiency Virus (HIV) Infection in TB Patients in Addis Ababa. Ethiopian Journal of Health 14(3): 277-282.

Federal HIVIAIDS Prevention and Control Office (2004). Guidelines for HCT in Ethiopia, Federal Ministry of Health, 1-27.
Sci. Technol. Arts Res. J., July-Sep 2012, 1(3): 24-30

Jammeh, A. (2007). Acceptability of VCT for HIV among Pregnant Women. Western Health Division, Gambia.

Melaku, M.D. (2007). Assessment of VCT Utilization and Willingness to Accept PIHCT among TB Patients in Addis Ababa. Public Health Department. Addis Ababa. Ethiopia.

Mukherjee, J.S., Farmer, P.E., Niyizonkiza, D., McCorkle, L., Vanderwarker, C., Teixeira, P., Kim, J.Y. (2003). Tackling HIV in Resource Poor Countries. BMJ 327: 1104-1106.

Paxton, S., Gonzales, G., Uppakaew, K., Abraham, K.K., Okta, S., Green, C., Nair, K.S., Merati, T.P., Thephthien, B., Marin, M., Quesada, A. (2005). AIDS-Related Discrimination in Asia. AIDS Care 17(4):413-24.

Stein, J.A., Nyamathi, A., (2000). Gender Differences in Behavioral and Psychosocial Predictors of HIV Testing and Return for Test Results in a High-Risk Population. AIDS Care 12(3):343-56.

The Public Health Agency of Canada. (2006): HIV Testing and Counseling Policy in Transition. International Public Health Dialogue on HIV Testing and Counseling Toronto.

USAID/Synergy: Women's Experiences with HIV Serodisclosure in Africa: Implications for VC and PMTCT. Meeting Report. Washington DC: USAID, 14-16.

WHO/UNAIDS (2004). UNAIDS/WHO Policy Statement on HIV Testing.

WHO: Cidsase Definitions of HIV for Surveillance, Revised Clinical Staging \& Immunological Classification of HIV-Related Disease in Adults \& Children. Geneva: WHO, 2-4.

Wilkinson, D., Wilkinson, N., Lombard, C., Martin, D., Smith, A., Floyd, K., Ballard, R. (1997). On-Site HIV Testing in Resource Poor Settings: is one rapid test enough? AIDS 11:377-381. 